\title{
Contribuições da sociopoética à produção científica sobre cuidar em enfermagem: revisão integrativa de literatura
}

\author{
Contributions of social poetics on the scientific production regarding nursing care: an integrative literature review
}

\author{
Contribuciones de la Sociopoética a la producción científica acerca de cuidar en enfermería: revisión integrativa de literatura
}

Iraci dos Santos ${ }^{1}$, Leandro Andrade da Silva², Jacques Henri Maurice Gauthier ${ }^{3}$, Renata Gomes Machado Guerra ${ }^{4}$

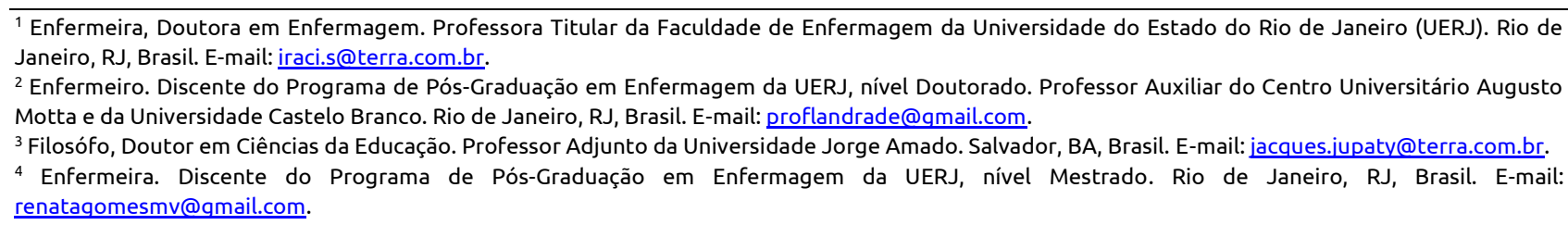

\section{RESUMO}

Pesquisas sociopoéticas são desenvolvidas no Brasil em diferentes áreas, predominando na enfermagem. Neste artigo, o objetivo foi verificar a contribuição da sociopoética na produção científica de enfermagem. Utilizou-se o método de revisão integrativa de literatura, considerando suas seis etapas. Acessando as bases de dados CUIDEN e BVS, de março a maio de 2012, foram selecionados 26 artigos que apresentavam estudos sociopoéticos, cujos dados foram submetidos à estatística descritiva e análise categorial. Nos resultados ressaltam-se as categorias: autocuidado (02); fundamentação teórica da sociopoética (09); cuidado de enfermagem em diferentes especialidades (15). Concluiu-se que o cuidar/educar/pesquisar predominou nos trabalhos selecionados, revelando a implicação ética dessa abordagem com os seres humanos. A maior contribuição da sociopoética refere-se à inovação epistemológica da prática de pesquisa. O método privilegia os informantes, valorizando seus saberes, crenças e culturas e favorecendo o exercício de sua cidadania na convivência com o mundo da saúde.

Descritores: Cuidados de Enfermagem; Educação em Saúde; Pesquisa Metodológica em Enfermagem; Pesquisa em Enfermagem.

\section{ABSTRACT}

Socio poetic studied are developed in Brazil in a range of disciplines, but mostly in nursing. The objective of this article was to identify the contribution of social poetics in the scientific production of nursing. An integrative literature review was performed, considering its six stages. Searching on the CUIDEN and BVS database, between March and May of 2012, a total 26 articles were selected, which presented socio poetic studies, of which data were submitted to descriptive statistics and categorical analysis. The following categories are highlighted: self-care (02); theoretical foundations of social poetics (09); nursing care across different specialties (15). In conclusion, care/education/research prevailed in the selected studies, thus revealing the ethical implication of this approach with human beings. The greatest contribution of socio poetics refers to the epistemological innovation of research practice. This method favors informants, valuing knowledge, beliefs and cultures and favoring citizenship in living with the health world.

Descriptors: Nursing Care; Health Education; Nursing Methodology Research; Nursing Research.

\section{RESUMEN}

Se desarrollan investigaciones sociopoéticas en Brasil en diferentes áreas, predominando la enfermería. Se objetivó verificar la contribución de la Sociopoética a la producción científica de enfermería. Se efectuó revisión integrativa de literatura, considerando sus seis etapas. Accediendo a las bases CUIDEN y BVS entre marzo y mayo de 2012, se seleccionaron 26 artículos, presentando estudios sociopoéticos sometiéndose los datos a estadística descriptiva y análisis categorial. En los resultados resaltan las categorías: autocuidado, (02); fundamentación teórica de la sociopoética, (09); cuidado de enfermería en diferentes especialidades, (15). Se concluyó en que el cuidar/educar/investigar predominó en los trabajos seleccionados, revelando la implicancia ética del abordaje con los seres humanos. La mayor contribución de la sociopoética refiere a la innovación epistemológica de la práctica investigativa. El método privilegia a los informantes, valorizando sus conocimientos, creencias y culturas; favoreciendo el ejercicio de su ciudadanía en la convivencia con el mundo de la salud.

Descriptores: Atención de Enfermería; Educación en Salud; Investigación Metodológica en Enfermería; Investigación en Enfermería. 


\section{INTRODUÇÃO}

A sociopoética tem origem nas vivências de Gauthier $^{(1)}$ no movimento sindical de luta de um povo indígena situado na Kanaky, também denominada Nova Caledônia, no Pacífico, que lutou por sua independência contra o colonialismo francês. Este povo inseriu em suas escolas uma pedagogia própria notadamente inspirada em Paulo Freire, na qual a criança se transformou em ser ativo, integrando saberes ancestrais aos conhecimentos científicos na busca do ecodesenvolvimento sustentável(2).

Em relação aos seus fundamentos teóricos, a sociopoética é uma continuação do amadurecimento da Pedagogia do Oprimido de Paulo Freire, uma outra leitura desta e acompanhada por outras inspirações como a Análise Institucional, tendência René Lourau, a Esquizoanálise de Gilles Deleuze e Félix Guattari, o Teatro do Oprimido de Augusto Boal e a Escuta Mitopoética de René Barbier ${ }^{(2)}$. Ela inova ao utilizar a ideia de cuidar em pesquisas científicas, principalmente na área de enfermagem. No Brasil, ganha uma nova dimensão a partir de implicações psicoafetivas, histórico existenciais, estruturais e profissionais, de Iraci dos Santos e de Jacques Gauthier que iniciaram a jornada intelectual acerca da sociopoética, nos anos 90.

Ao longo de quase duas décadas, novos estudos vêm sendo elaborados com base nos pressupostos filosóficos, teórico-metodológicos e tecnológicos desta abordagem. Assim, teve-se como objetivo verificar a contribuição da sociopoética na produção científica de enfermagem. A intenção é oferecer subsídios para a reflexão e análise sobre o estado da arte do cuidar em pesquisas científicas, na área de enfermagem, que utilizaram os princípios filosóficos e os fundamentos teóricos da sociopoética.

\section{MÉTODO}

Escolheu-se a Revisão Integrativa de Literatura (RIL), cuja busca por estudos científicos considera critérios de inclusão e exclusão explícitos, avaliação da qualidade metodológica, e na quantificação das publicações aplicase técnicas estatísticas ${ }^{(3)}$. Foram respeitadas rigorosamente as seis etapas da RIL.

Primeira - Escolha da questão norteadora: qual é a contribuição da sociopoética para o desenvolvimento de estudos em enfermagem sobre o cuidar/educar/pesquisar? Segunda - Busca nas bases de dados eletrônicas: Fundación Index (CUIDEN) e Biblioteca Virtual de Saúde (BVS). Realizada de março a maio de 2012, utilizando a expressão sociopoética, pois inexistem descritores padronizados nos Descritores em Ciências da Saúde que congreguem termos aproximados aos de interesse desta RIL.

Terceira - Seleção dos trabalhos segundo o critério de inclusão: publicações de estudos sociopoéticos do período de 2000 a 2011, idioma português, inglês e espanhol, com resumos e textos completos disponíveis online nas bases de dados citadas. Critério de exclusão: artigos cuja descrição não se referia à temática do estudo. Identificou-se 28 trabalhos, dos quais 26 foram selecionados para esta RIL. Quarta - Garantia do rigor metodológico, elaborando-se formulário composto por variáveis relacionadas à identificação do artigo(3): ano e periódico de publicação; caracterização dos estudos; titulação dos autores; sujeitos de pesquisa, e síntese dos resultados. Aos dados produzidos aplicou-se a estatística descritiva simples, e análise categorial característica da sociopoética(2), sendo estes representados graficamente em quadros demonstrativos.

Quinta - Análise crítica dos trabalhos selecionados, comparando-se os conhecimentos teóricos, a identificação de conclusões e implicações resultantes da RIL. O que possibilitou a compreensão sobre o estado da arte da produção de conhecimento na área da enfermagem sobre o cuidar/educar/pesquisar, alicerçado nos princípios filosóficos e pressupostos teóricometodológicos da sociopoética.

Sexta e última etapa - Revisão/síntese do conhecimento produzido incluindo-se as informações que permitiram avaliar a pertinência dos princípios e pressupostos do método utilizado. Nesta RIL, a identificação do nível de evidência dos 26 artigos considerou a utilização, em todos eles, da sociopoética, uma abordagem qualitativa, que subentende o nível de evidência quatro, de acordo com Agency for Healthcare Research and Quality(3) (AHRQ). Destaca-se que, considerando os dados produzidos, delimitou-se 11 categorias/áreas temáticas referentes ao cuidar/educar/pesquisar em enfermagem, destacando-se a fundamentação filosófica e teórica da sociopoética.

Uma limitação do estudo é a predominância de artigos resultantes de teses, dissertações e trabalhos de conclusão de curso (TCC) acessados via online. Visto haver 
ampla disseminação de trabalhos em sociopoética, inclusive em periódicos online, a exemplo da Entrelugares ${ }^{(1-2)}$ publicado pela Universidade Federal do Ceará, classificado junto à CAPES como Qualis B-4, e em teses, dissertações e monografias arquivadas em bibliotecas de cursos de pós-graduação stricto e latosensu.

\section{RESULTADOS}

Delimitando o perfil das produções científicas em enfermagem, utilizando o método sociopoético e/ou explicitando seus princípios filosóficos e fundamentos teóricos; ressalta-se que seus produtores são predominantemente enfermeiros docentes e pósgraduandos em enfermagem. Entre os sujeitos de pesquisa situam-se clientes, familiares de clientes, estudantes e profissionais desta área do conhecimento e pessoas idosas vinculadas a Universidade Aberta à Terceira Idade da Universidade do Estado do Rio de Janeiro. O idioma predominante de publicação foi o português, embora tenha sido publicado um artigo em espanhol no Index Enfermería(4), aqui utilizado, também, como referência teórica. No período de 2000 a 2011, só não foram encontrados artigos em 2001, 2002 e 2005. A disseminação do método realizou-se em periódicos científicos qualificados. Registra-se que, do total de 26 artigos, 17 situaram-se na modalidade de original e nove são artigos teóricos (4-12).
Os artigos foram caracterizados por área temática nas seguintes categorias: autocuidado, dois; teorização/fundamentação da sociopoética, nove; cuidado de Enfermagem em diferentes especialidades, 15, sendo esta última delimitada em nove subcategorias: saúde mental, três; saúde do idoso, três; nefrologia, três; e um, respectivamente em dermatologia, obstetrícia, saúde do adolescente, estratégia de saúde da família, terapia intensiva e HIV/AIDS.

A categoria Autocuidado (AC) refere-se a dois estudos(13-14), entre os quais um grupo pesquisador (GP) foi composto por estudantes(13). A síntese dos seus resultados evidencia a importância da orientação de enfermagem, visando à promoção da saúde nas dimensões corporais, desde a identificação de necessidades de AC. Esta é uma responsabilidade das instituições de ensino com o objetivo de crescimento pessoal e profissional. Na pesquisa realizada em unidade de traumato ortopedia, o GP alertou que os enfermeiros devem ser capazes de conduzir o atendimento aos clientes em condições complexas ${ }^{(13)}$. Pois o ambiente de cuidado sofre contínuas transformações, sendo o desenvolvimento consciente dos sentidos corporais um instrumento próprio ao atendimento de enfermagem. Este permite a eficiente identificação dos problemas, planejamento e intervenções holísticas e qualificadas. Para tal orientação é imprescindível utilizar instrumentos compatíveis com a criatividade e humanidade das pessoas $^{(1-2)}$ (Quadro 1).

Quadro 1: Caracterização dos estudos sociopoéticos investigados. Rio de Janeiro, RJ, 2012.

\begin{tabular}{|c|c|c|c|c|c|}
\hline Área temática & Ano & Autores & Periódico & Titulo & Síntese dos resultados \\
\hline \multirow[t]{2}{*}{ Autocuidado } & 2009 & $\begin{array}{c}\text { Brandão ES, } \\
\text { Santos I dos, } \\
\text { Cavalcanti } \\
\text { ACD, Santana } \\
\text { RF, Quelluci } \\
\text { GC, Azevedo } \\
\text { SL. }\end{array}$ & $\begin{array}{l}\text { Rev Gaúcha } \\
\text { Enferm }\end{array}$ & $\begin{array}{l}\text { Uma sociopoética do } \\
\text { autocuidado: } \\
\text { comportamento de } \\
\text { estudantes de } \\
\text { enfermagem visando } \\
\text { à promoção da saúde. }\end{array}$ & $\begin{array}{c}\text { Evidenciou a necessidade de se preparar } \\
\text { os alunos para o autocuidado como forma } \\
\text { de exercitarem a prática de promoção da } \\
\text { saúde. Pois os participantes relataram um } \\
\text { descuidar de si, justificado pela } \\
\text { indisponibilidade de tempo para isto. O } \\
\text { estudo alertou a necessidade de reflexão } \\
\text { sobre outros aspectos que envolvem o } \\
\text { processo de formação, a exemplo dos } \\
\text { físicos, sociais, emocionais e espirituais. }\end{array}$ \\
\hline & 2011 & $\begin{array}{l}\text { Cameron LE, } \\
\text { Araújo STC. }\end{array}$ & $\begin{array}{c}\text { Rev Esc } \\
\text { Enferm USP }\end{array}$ & $\begin{array}{l}\text { Visão como } \\
\text { instrumento da } \\
\text { percepção na } \\
\text { assistência em } \\
\text { enfermagem } \\
\text { traumato-ortopédica. }\end{array}$ & $\begin{array}{l}\text { Possibilitou refletir sobre a adequação de } \\
\text { cuidados às necessidades do cliente e de } \\
\text { desenvolvimento consciente dos sentidos } \\
\text { corporais como instrumento do } \\
\text { atendimento de enfermagem. }\end{array}$ \\
\hline $\begin{array}{c}\text { Teorização e } \\
\text { fundamentação } \\
\text { da sociopoética }\end{array}$ & 2003 & Gauthier JZ. & $\begin{array}{c}\text { Rev Enferm } \\
\text { UERJ }\end{array}$ & $\begin{array}{c}\text { Metáfora e conceito } \\
\text { em pesquisas } \\
\text { qualitativas. }\end{array}$ & $\begin{array}{c}\text { Promoveu a criação de sentidos } \\
\text { inovadores pelo grupo pesquisador (GP) } \\
\text { considerando-o como um filósofo } \\
\text { coletivo. }\end{array}$ \\
\hline
\end{tabular}




\begin{tabular}{|c|c|c|c|c|c|}
\hline Área temática & Ano & Autores & Periódico & Titulo & Síntese dos resultados \\
\hline & 2008 & $\begin{array}{l}\text { Silveira LC, } \\
\text { Almeida ANS, } \\
\text { Macedo SM, } \\
\text { Alencar MN, } \\
\text { Araújo MAM. }\end{array}$ & Interface & $\begin{array}{l}\text { A sociopoética como } \\
\text { dispositivo para } \\
\text { produção de } \\
\text { conhecimento. }\end{array}$ & $\begin{array}{c}\text { Ampliou a discussão sobre as } \\
\text { contribuições da sociopoética em } \\
\text { pesquisas científicas através de uma } \\
\text { abordagem subjetiva, em práticas de } \\
\text { produção de conhecimento } \\
\text { comprometidas com a valorização da } \\
\text { diferença e o estímulo aos novos } \\
\text { processos de subjetivação. }\end{array}$ \\
\hline & 2008 & Gauthier JZJ. & $\begin{array}{l}\text { Rev. } \\
\text { Enferm. } \\
\text { UERJ }\end{array}$ & $\begin{array}{l}\text { Pour une réflexion } \\
\text { anticolonialiste sur } \\
\text { l'autorisation } \\
\text { noétique, spirituelle, } \\
\text { corporelle et } \\
\text { politique des } \\
\text { chercheurs. }\end{array}$ & $\begin{array}{l}\text { Demonstrou como a sociopoética permite } \\
\text { evitar uma colonização dos corpos dos } \\
\text { pesquisadores pela Academia. Essa } \\
\text { colonização é a regra e constitui-se em } \\
\text { obstáculo político ao conhecimento e ao } \\
\text { desenvolvimento espiritual. }\end{array}$ \\
\hline & 2007 & Santos I dos. & $\begin{array}{c}\text { Rev Enferm } \\
\text { UERJ }\end{array}$ & $\begin{array}{l}\text { Cuidando do } \\
\text { educando: a } \\
\text { sociopoética } \\
\text { sensibilizando a } \\
\text { formação do } \\
\text { cuidador. }\end{array}$ & $\begin{array}{c}\text { Revelou a responsabilidade das } \\
\text { instituições de ensino de enfermagem. } \\
\text { Demonstrou que o educar/cuidar pode } \\
\text { ser realizado em conjunto por } \\
\text { professores e alunos, visando o } \\
\text { desenvolvimento pessoal além da } \\
\text { formação profissional. }\end{array}$ \\
\hline & 2006 & $\begin{array}{l}\text { Santos I dos, } \\
\text { Gauthier J, } \\
\text { Figueiredo } \\
\text { NMA, Tavares } \\
\text { CMM, Brandão } \\
\text { ES, Santana RF }\end{array}$ & $\begin{array}{l}\text { Texto } \\
\text { contexto } \\
\text { Enferm }\end{array}$ & $\begin{array}{l}\text { A perspectiva } \\
\text { estética no } \\
\text { cuidar/educar junto } \\
\text { às pessoas: } \\
\text { apropriação e } \\
\text { contribuição da } \\
\text { sociopoética. }\end{array}$ & $\begin{array}{c}\text { Apresentou novas modalidades de } \\
\text { cuidado orientadoras do } \\
\text { desenvolvimento de instrumentos } \\
\text { metodológicos e tecnológicos } \\
\text { indispensáveis à enfermagem, e também } \\
\text { contribuiu para a transformação poética } \\
\text { das pessoas. As novas modalidades } \\
\text { caracterizaram um cuidado/educação } \\
\text { mais humano. }\end{array}$ \\
\hline & 2009 & $\begin{array}{c}\text { Santos I dos, } \\
\text { Brandão ES, } \\
\text { Clos AC. }\end{array}$ & $\begin{array}{l}\text { Rev. } \\
\text { Enferm. } \\
\text { UERJ }\end{array}$ & $\begin{array}{c}\text { Enfermagem } \\
\text { dermatológica: } \\
\text { competências e } \\
\text { tecnologia da escuta } \\
\text { sensível para atuar } \\
\text { nos cuidados com a } \\
\text { pele. }\end{array}$ & $\begin{array}{l}\text { Destacou a importância dos cuidados com } \\
\text { a pele das pessoas. Isto possibilita à } \\
\text { equipe de enfermagem um exercício de } \\
\text { observação, escuta sensível da pessoa } \\
\text { com afecção cutânea, e a decodificação } \\
\text { de sinais e sintomas viabilizados através } \\
\text { deste fundamental canal de comunicação } \\
\text { que é a pele dos sujeitos cuidados. }\end{array}$ \\
\hline & 2010 & $\begin{array}{l}\text { Santos I, Alves } \\
\text { ACS, Silva FSS, } \\
\text { Penna LHG, } \\
\text { Alvin NAT. }\end{array}$ & $\begin{array}{c}\text { Rev. Bras. } \\
\text { Enferm }\end{array}$ & $\begin{array}{l}\text { Fundamentos } \\
\text { filosóficos e teóricos } \\
\text { para novas } \\
\text { concepções de cuidar } \\
\text { em enfermagem. }\end{array}$ & $\begin{array}{l}\text { Este trabalho identificou a aplicação de } \\
\text { princípios filosóficos e fundamentos } \\
\text { teóricos da sociopoética em novas } \\
\text { concepções do cuidar. Através da revisão } \\
\text { sistemática de literatura, foi possível } \\
\text { verificar as novas concepções do cuidar, o } \\
\text { cliente é o principal alvo do trabalho em } \\
\text { enfermagem. Os fundamentos da } \\
\text { sociopoética foram aplicados revelando } \\
\text { uma perspectiva onde a ética do cuidar, } \\
\text { traduziu-se no respeito aos clientes e aos } \\
\text { seus saberes para o autocuidado, conduz } \\
\text { à autonomia e à solidariedade entre estes } \\
\text { e os profissionais. }\end{array}$ \\
\hline & 2000 & $\begin{array}{c}\text { Figueiredo } \\
\text { NMA, Santos I } \\
\text { dos. }\end{array}$ & $\begin{array}{l}\text { Esc. Anna } \\
\text { Nery Rev. } \\
\text { Enferm }\end{array}$ & $\begin{array}{l}\text { Nascendo para } \\
\text { aprender: } \\
\text { entendendo o } \\
\text { cuidado em saúde e } \\
\text { enfermagem. }\end{array}$ & $\begin{array}{c}\text { Evidenciou que o cuidar em enfermagem } \\
\text { é influenciado por quem o aplica, } \\
\text { levando-se em consideração as } \\
\text { implicações pessoais dos profissionais. }\end{array}$ \\
\hline
\end{tabular}




\begin{tabular}{|c|c|c|c|c|c|}
\hline Área temática & Ano & Autores & Periódico & Titulo & Síntese dos resultados \\
\hline & 2006 & Santos I dos. & $\begin{array}{l}\text { Rev Index } \\
\text { Enfermería }\end{array}$ & $\begin{array}{c}\text { Sociopoética. Un } \\
\text { Puente para el cuidar } \\
\text { / investigar en } \\
\text { enfermería. }\end{array}$ & $\begin{array}{l}\text { Ressaltou, que a sociopoética institui para } \\
\text { a enfermagem uma perspectiva ética, } \\
\text { revelada no respeito aos clientes e aos } \\
\text { seus saberes para o autocuidado, } \\
\text { conduzindo à autonomia e à } \\
\text { solidariedade entre estes e os } \\
\text { profissionais. Destaca as concepções de } \\
\text { cuidar em enfermagem, através desta } \\
\text { abordagem, explicando } \\
\text { metodologicamente sua aplicabilidade às } \\
\text { pesquisas científicas. }\end{array}$ \\
\hline \multirow{3}{*}{$\begin{array}{l}\text { Cuidado da } \\
\text { pessoa idosa }\end{array}$} & 2005 & $\begin{array}{l}\text { Santana RF, } \\
\text { Santos I dos }\end{array}$ & $\begin{array}{l}\text { Esc. Anna } \\
\text { Nery Rev. } \\
\text { Enferm }\end{array}$ & $\begin{array}{l}\text { Teorizando o } \\
\text { envelhecer para } \\
\text { cuidar da pessoa } \\
\text { idosa: estudo } \\
\text { sociopoético. }\end{array}$ & $\begin{array}{l}\text { Ampliou a discussão sobre a importância } \\
\text { de ações de enfermagem no cuidado de } \\
\text { idosos, possibilitando ao GP uma maior } \\
\text { compreensão da importância do } \\
\text { autocuidado (AC) para o envelhecimento } \\
\text { saudável. }\end{array}$ \\
\hline & 2010 & $\begin{array}{c}\text { Silva ACS, } \\
\text { Santos I dos. }\end{array}$ & $\begin{array}{l}\text { Texto } \\
\text { contexto } \\
\text { Enferm. }\end{array}$ & $\begin{array}{l}\text { Promoção do } \\
\text { autocuidado de } \\
\text { idosos para o } \\
\text { envelhecer saudável: } \\
\text { aplicação da teoria de } \\
\text { Nola Pender. }\end{array}$ & $\begin{array}{l}\text { Revelou que, ao cuidar do corpo, a pessoa } \\
\text { idosa passa a compreender melhor e de } \\
\text { maneira mais construtiva a sua própria } \\
\text { vida. O AC com o corpo exige do indivíduo } \\
\text { conhecimentos e também a observação } \\
\text { de si próprio para a tomada de } \\
\text { consciência daquilo que lhe faz mal no } \\
\text { seu hábito de agir e de pensar. }\end{array}$ \\
\hline & 2011 & $\begin{array}{c}\text { Santos I dos, } \\
\text { Alves ACS, } \\
\text { Silva AFL, } \\
\text { Caldas CP, } \\
\text { Berardinelli } \\
\text { LMM, Santana } \\
\text { RF. }\end{array}$ & $\begin{array}{l}\text { Esc. Anna } \\
\text { Nery Rev. } \\
\text { Enferm }\end{array}$ & $\begin{array}{l}\text { O grupo pesquisador } \\
\text { construindo ações de } \\
\text { autocuidado para o } \\
\text { envelhecimento } \\
\text { saudável: pesquisa } \\
\text { sociopoética. }\end{array}$ & $\begin{array}{c}\text { Sobrelevou a preocupação do GP em } \\
\text { cuidar de sua saúde. Através dos } \\
\text { conhecimentos produzidos verificou-se } \\
\text { que ser pessoa idosa, na atualidade, é } \\
\text { adotar decisões positivas para reagir às } \\
\text { adversidades provocadas pelo } \\
\text { envelhecimento, utilizando seu potencial } \\
\text { humano para viver com qualidade, apesar } \\
\text { dos possíveis adoecimentos e perdas } \\
\text { financeiras, econômicas e afetivas }\end{array}$ \\
\hline \multirow{3}{*}{$\begin{array}{l}\text { Cuidado de } \\
\text { enfermagem em } \\
\text { saúde mental }\end{array}$} & 2006 & Tavares CMM & $\begin{array}{l}\text { Esc. Anna } \\
\text { Nery Rev. } \\
\text { Enferm }\end{array}$ & $\begin{array}{l}\text { Análise crítica de uma } \\
\text { experiência de } \\
\text { integração do estágio } \\
\text { de enfermagem em } \\
\text { saúde mental ao SUS. }\end{array}$ & $\begin{array}{l}\text { Evidenciou fatores impeditivos ao } \\
\text { desenvolvimento da prática criativa do } \\
\text { cuidar em enfermagem psiquiátrica. }\end{array}$ \\
\hline & 2004 & $\begin{array}{l}\text { Silveira LC, } \\
\text { Braga VAB. }\end{array}$ & $\begin{array}{l}\text { Rev. Esc. } \\
\text { Enferm. } \\
\text { USP }\end{array}$ & $\begin{array}{l}\text { A equipe de saúde } \\
\text { mental numa } \\
\text { aproximação } \\
\text { sociopoética: das } \\
\text { relações } \\
\text { interpessoais à } \\
\text { produção de } \\
\text { subjetividade. }\end{array}$ & $\begin{array}{c}\text { Possibilitou ao grupo de trabalhadores de } \\
\text { saúde mental a reflexão e autoanálise } \\
\text { para repensar as suas práticas, } \\
\text { aumentando, assim, a produção de } \\
\text { sentidos. }\end{array}$ \\
\hline & 2007 & $\begin{array}{l}\text { Silveira LC, } \\
\text { Braga VAB, } \\
\text { Petit SH. }\end{array}$ & $\begin{array}{l}\text { Online } \\
\text { Brazilian } \\
\text { Journal of } \\
\text { Nursing }\end{array}$ & $\begin{array}{l}\text { A produção de } \\
\text { subjetividade dos } \\
\text { usuários de um } \\
\text { hospital-dia: uma } \\
\text { experiência } \\
\text { sociopoética. }\end{array}$ & $\begin{array}{l}\text { Incentivou o exercício da cidadania entre } \\
\text { os sujeitos do cuidado, identificando } \\
\text { "seus" mecanismos de desejo para evitar } \\
\text { receber um cuidado baseado em } \\
\text { necessidades preestabelecidas. } \\
\text { Possibilitou ao profissional de } \\
\text { enfermagem resgatar o aspecto artístico } \\
\text { (ético-estético), tão preterido em sua } \\
\text { prática em função da biologização de } \\
\text { todos os processos. }\end{array}$ \\
\hline $\begin{array}{c}\text { Cuidado de } \\
\text { enfermagem em } \\
\text { saúde do } \\
\text { adolescente }\end{array}$ & 2003 & $\begin{array}{l}\text { Moraes LMP, } \\
\text { Braga VAB, } \\
\text { Silveira LC. }\end{array}$ & $\begin{array}{l}\text { Rev. Baiana } \\
\text { Enferm }\end{array}$ & $\begin{array}{l}\text { Sociopoética e } \\
\text { enfermagem: uma } \\
\text { aproximação na } \\
\text { pesquisa com } \\
\text { adolescentes. }\end{array}$ & $\begin{array}{c}\text { Descreveu a aplicabilidade da } \\
\text { sociopoética junto às adolescentes, } \\
\text { enfatizando as dimensões afetivas, } \\
\text { sensitivas, intuitivas, imaginativas e } \\
\text { racionais no processo de pesquisar em } \\
\text { enfermagem. }\end{array}$ \\
\hline
\end{tabular}




\begin{tabular}{|c|c|c|c|c|c|}
\hline Área temática & Ano & Autores & Periódico & Titulo & Síntese dos resultados \\
\hline \multirow{4}{*}{$\begin{array}{l}\text { Cuidado de } \\
\text { enfermagem em } \\
\text { nefrologia }\end{array}$} & 2008 & $\begin{array}{l}\text { Cruz DOA, } \\
\text { Araújo STC. }\end{array}$ & $\begin{array}{c}\text { Acta Paul. } \\
\text { Enferm. }\end{array}$ & $\begin{array}{l}\text { Diálise peritoneal: a } \\
\text { percepção tátil do } \\
\text { cliente na convivência } \\
\text { com o cateter. }\end{array}$ & $\begin{array}{c}\text { Revelou mediante vivências que } \\
\text { valorizaram o corpo a necessidade de } \\
\text { cuidados de enfermagem essenciais ao } \\
\text { apoio psicoafetivo dos clientes e na } \\
\text { manutenção e integridade incessante do } \\
\text { cateter de diálise. }\end{array}$ \\
\hline & 2009 & $\begin{array}{c}\text { Araújo STC, } \\
\text { Cruz DOA. }\end{array}$ & $\begin{array}{c}\text { Acta Paul. } \\
\text { Enferm. }\end{array}$ & $\begin{array}{c}\text { Pesquisa } \\
\text { sociopoética: a } \\
\text { subjetividade de } \\
\text { pacientes em terapias } \\
\text { substitutivas renais. }\end{array}$ & $\begin{array}{c}\text { Possibilitou aos participantes } \\
\text { expressarem as suas percepções sobre o } \\
\text { cuidado de enfermagem em situações de } \\
\text { prazer e de sofrimento. Destacou, } \\
\text { também, a dificuldade dos clientes } \\
\text { conviverem com o cateter de diálise. }\end{array}$ \\
\hline & 2010 & $\begin{array}{l}\text { Cruz DOA, } \\
\text { Araújo STC. }\end{array}$ & $\begin{array}{l}\text { Rev. } \\
\text { Pesquisa } \\
\text { Cuidado } \\
\text { Fundam }\end{array}$ & $\begin{array}{l}\text { Comunicação não- } \\
\text { verbal e o corpo } \\
\text { transformado: } \\
\text { convivência com o } \\
\text { cateter de diálise } \\
\text { peritoneal. }\end{array}$ & $\begin{array}{c}\text { Permitiu compreender as reações } \\
\text { comportamentais do GP ao se defrontar } \\
\text { com a doença renal e o tratamento } \\
\text { dialítico. }\end{array}$ \\
\hline & 2010 & $\begin{array}{l}\text { Coelho JAB, } \\
\text { Araújo STC. }\end{array}$ & $\begin{array}{c}\text { Acta Paul. } \\
\text { Enferm }\end{array}$ & $\begin{array}{l}\text { Desgaste da equipe } \\
\text { de enfermagem no } \\
\text { centro de tratamento } \\
\text { de queimados. }\end{array}$ & $\begin{array}{c}\text { Possibilitou a expressão de sentidos } \\
\text { corporais e a verbalização da dificuldade } \\
\text { ao cuidar de pessoas queimadas, entre } \\
\text { alguns membros da equipe de } \\
\text { enfermagem. Através da estimulação dos } \\
\text { sentidos corporais foi possível capacitar } \\
\text { os profissionais, visando ao cuidado } \\
\text { efetivo. Pois os sentidos permitiram } \\
\text { entender melhor o ambiente que os } \\
\text { cercava. }\end{array}$ \\
\hline $\begin{array}{l}\text { Cuidado de } \\
\text { enfermagem em } \\
\text { obstetrícia }\end{array}$ & 2008 & $\begin{array}{l}\text { Torres JA, } \\
\text { Santos I dos, } \\
\text { Vargens OMC. }\end{array}$ & $\begin{array}{l}\text { Texto } \\
\text { Contexto } \\
\text { Enferm }\end{array}$ & $\begin{array}{l}\text { Construindo uma } \\
\text { concepção de } \\
\text { tecnologia de } \\
\text { cuidado de } \\
\text { enfermagem } \\
\text { obstétrica: estudo } \\
\text { sociopoético. }\end{array}$ & $\begin{array}{c}\text { Enfatizou a importância da } \\
\text { potencialização do cuidado materno. Pois } \\
\text { gerando um ganho individual e social e } \\
\text { mediante a vivência de lugares } \\
\text { geomíticos foi possível elaborar sete dos } \\
\text { doze atributos da concepção de } \\
\text { tecnologia não invasiva de cuidar em } \\
\text { enfermagem. Destaca-se, também, a } \\
\text { diferença de cuidados em relação ao } \\
\text { gênero. Sendo, o feminino predominante } \\
\text { nas ações de enfermagem foi descrito } \\
\text { pelo GP como considerado de menos valia } \\
\text { no espaço hospitalar, no qual predomina } \\
\text { o poder da figura masculina. }\end{array}$ \\
\hline $\begin{array}{l}\text { Cuidado de } \\
\text { enfermagem na } \\
\text { estratégia saúde } \\
\text { da família }\end{array}$ & 2008 & $\begin{array}{l}\text { Gomes MEA, } \\
\text { Silveira LC, } \\
\text { Petit SH, } \\
\text { Brasileiro } \\
\text { GMV, Almeida } \\
\text { ANS. }\end{array}$ & $\begin{array}{l}\text { Rev. Latino- } \\
\text { Am. Enferm }\end{array}$ & $\begin{array}{l}\text { A sexualidade das } \\
\text { mulheres atendidas } \\
\text { no programa saúde } \\
\text { da família: uma } \\
\text { produção } \\
\text { sociopoética. }\end{array}$ & $\begin{array}{c}\text { Relatou a necessidade de descristalização } \\
\text { dos profissionais de saúde quanto às } \\
\text { necessidades do cuidado humano, } \\
\text { ampliando as práticas de cuidar através } \\
\text { do toque e orientadas para o autocuidado } \\
\text { das mulheres. }\end{array}$ \\
\hline $\begin{array}{l}\text { Cuidado de } \\
\text { enfermagem em } \\
\text { unidade de } \\
\text { terapia intensiva }\end{array}$ & 2010 & $\begin{array}{c}\text { Silva FS, } \\
\text { Santos I dos. }\end{array}$ & $\begin{array}{l}\text { Esc. Anna } \\
\text { Nery Rev. } \\
\text { Enferm }\end{array}$ & $\begin{array}{l}\text { Expectativas de } \\
\text { familiares de clientes } \\
\text { em unidade de } \\
\text { terapia intensiva } \\
\text { sobre o atendimento } \\
\text { em saúde: estudo } \\
\text { sociopoético. }\end{array}$ & $\begin{array}{l}\text { Revelou a necessidade de cuidado para } \\
\text { com a família de clientes hospitalizados. } \\
\text { As falas do GP evidenciaram a } \\
\text { importância do atendimento humanizado. } \\
\text { Fato que permite aos usuários um modo } \\
\text { melhor de lidar com a internação em } \\
\text { unidade de terapia intensiva. }\end{array}$ \\
\hline $\begin{array}{l}\text { Cuidado de } \\
\text { enfermagem às } \\
\text { pessoas que } \\
\text { convivem com o } \\
\text { HIV/AIDS }\end{array}$ & 2010 & $\begin{array}{c}\text { Almeida ANS, } \\
\text { Silveira LC, } \\
\text { Silva MRF, } \\
\text { Araújo MAM, } \\
\text { Guimarães TA. }\end{array}$ & $\begin{array}{l}\text { Rev. Latino- } \\
\text { Am. Enferm }\end{array}$ & $\begin{array}{l}\text { Produção de } \\
\text { subjetividade e } \\
\text { sexualidade em } \\
\text { mulheres vivendo } \\
\text { com o HIV/Aids: uma } \\
\text { produção } \\
\text { sociopoética. }\end{array}$ & $\begin{array}{l}\text { Favoreceu as mulheres com o vírus } \\
\text { HIV/AIDS estabelecer outra maneira de } \\
\text { lidar afetivamente com sua sexualidade. }\end{array}$ \\
\hline
\end{tabular}

Compõem a categoria Teorização e fundamentação da sociopoética nove estudos ${ }^{(4-12)}$ que teorizam os avanços deste método no campo da pesquisa acadêmica e a sua importância para implementar cuidados em 
enfermagem. Destacam que, os novos conhecimentos sobre concepções teóricas instituem uma perspectiva ressaltando o exercício da cidadania entre profissionais e clientes, a ser viabilizada mediante práticas instituintes e adoção da escuta mito poética proposta por Barbier. No artigo da área de dermatologia sobressaiu a exigência de capacitação da equipe de enfermagem para cuidar dos clientes, considerando mais a sua integralidade e equilíbrio corporal, do que o privilegiar os curativos para as suas afecções cutâneas.

Entre os três trabalhos sobre Cuidado da pessoa idosa relevam-se a orientação de enfermagem para o envelhecimento saudável, que foi desenvolvida através do cuidar/educar/pesquisar em oficinas sociopoéticas. Tal orientação demonstrou que, cuidando do próprio corpo, a pessoa idosa compreende construtivamente o seu modo de agir e de pensar para o bem e/ou para o malestar na sua própria vida. Uma contribuição dos conhecimentos produzidos com a sociopoética foi a adoção, por parte desses sujeitos, de decisões positivas e a utilização de seu potencial humano para viver com qualidade.

Constatou-se nas publicações sobre o cuidado de enfermagem em diversas especialidades ( $\mathrm{N}-15)$, que entre as contribuições advindas da pesquisa sociopoética, destaca-se, predominantemente, o crescimento pessoal e a autorrealização dos membros do $\mathrm{GP}^{(1-2)}$. Tal fato se evidencia na categoria Cuidado de enfermagem em saúde mental, ressaltando que o método propicia aos profissionais desta área a reflexão e autoanálise para repensar as suas práticas aumentando, assim, a produção de sentidos do seu cotidiano de viver e trabalhar. Quanto a este conhecimento, sobreleva-se a evidência de fatores impeditivos ao desenvolvimento da prática criativa do cuidar em enfermagem psiquiátrica.

Nos estudos nos quais os membros do GP eram clientes observou-se a promoção do exercício da cidadania, ao se identificar "seus" mecanismos de desejo para evitar receber um cuidado baseado em necessidades preestabelecidas institucionalmente. Isto foi favorecido ao se resgatar o aspecto artístico (ético-estético), sempre relegado devido à biologização dos processos na área de saúde.

A utilização das principais ferramentas da sociopoética, quais sejam o desvelar do imaginário e a instituição do grupo pesquisador (GP), aplicadas no desenvolvimento das três pesquisas junto aos clientes com doença renal crônica, possibilitou a compreensão das imagens armazenadas e a revelação do inconsciente, e a busca das diferentes reações comportamentais que as pessoas apresentam ao se defrontar com a doença. Observou-se a valorização do corpo como fonte de conhecimento revelando as necessidades (prazer e sofrimento) de cuidados indispensáveis ao apoio psicoafetivo do GP na manutenção e integridade do cateter de diálise. Nesta situação, destaca-se a arte de enfermagem.

Ressaltam-se no cuidado junto às pessoas com queimaduras a expressão de sentidos corporais e a expressão da dificuldade por parte dos profissionais de enfermagem. Рага estes, o enfrentamento da dor do cliente lhes causa tristeza, estresse, cansaço físico e psicológico. Uma contribuição da estimulação dos sentidos corporais, na pesquisa sociopoética, é a capacitação dos profissionais para um cuidado efetivo, desde um maior entendimento do ambiente que os cerca.

Os resultados da pesquisa sociopoética da área de enfermagem obstétrica contribuíram para o exercício da cidadania/autonomia das profissionais desta área e suas respectivas clientes, ao revelar a potencialidade à institucionalização do cuidado materno nas casas de parto natural e a classificação de diversas tecnologias não invasivas, consequente ganho individual e social para a enfermagem e a saúde da mulher. Ressalta-se a produção do confeto (conceito+afeto), um neologismo criado por Gauthier, ou seja, a mistura de afeto e de conceito, que surge geralmente de grupos pesquisadores, no quadro de dispositivos sociopoéticos ${ }^{(2)}$, produzido em oficina de cuidar em enfermagem: o cuidado depende de quem o aplica, visto relacionar-se às implicações pessoais, profissionais e institucionais do ambiente de trabalho.

Foi encontrado apenas um artigo, respectivamente, nas áreas de estratégia saúde da família, unidade de terapia intensiva (UTI), HIV/AIDS, e saúde do adolescente, destacando-se a aplicabilidade da sociopoética a estas modalidades de áreas e singularidades dos sujeitos de pesquisa. Tal fato relaciona-se ao favorecimento das expressões de: aspectos afetivos, sensitivos, intuitivos, e racionais; sentimentos quanto à qualidade do cuidado no ambiente terapêutico; significados referentes à sexualidade; evidência de que os comportamentos de cuidar resultam do ambiente de cuidado. A pesquisa junto 
às adolescentes enfatizou a propriedade da sociopoética na revelação da expressão das dimensões afetivas, sensitivas e imaginativas durante o processo de cuidar/pesquisar em enfermagem.

\section{DISCUSSÃO}

Os artigos sobre autocuidado evidenciaram ao pesquisador e sujeitos de pesquisa uma concepção que vislumbra a importância da expressão verbal e corporal, do acolhimento, da liberdade para expressar sentimentos, da promoção da expressão da autoimagem, autoestima e do autocuidado entre ambos ${ }^{(14)}$.

$\mathrm{Na}$ categoria teorização e fundamentação da sociopoética os artigos difundem seu interesse na procura do sentido da vida dos grupos humanos e nas possibilidades de criação coletiva e cooperativa do conhecimento $^{(2,15)}$. Nesses trabalhos, ressalta-se que o papel do pesquisador é adotar uma postura de respeito mútuo, favorecendo o intercâmbio entre conhecimentos acadêmicos e de senso comum(2). No que se refere à formação profissional em enfermagem, ressaltou-se que antes de ensinar o funcionamento biológico, psicológico e social do ser humano, é necessário instrumentalizar o futuro cuidador, possibilitando que ele possa comunicarse e interagir com o cliente ${ }^{(14)}$. A sociopoética(2), como prática educativa, sinaliza aos docentes que 0 conhecimento é intelectual, gestual, intuitivo, emotivo, sensitivo. Fato revelado por alunos e reconhecido por educadores, pois ensinar é também aprender, é cuidar ${ }^{(5)}$. Sob essa perspectiva, a sociopoética extrapola os limites da pesquisa constituindo-se como uma filosofia de vida $^{(2,15-16)}$.

Referente ao Cuidado de enfermagem em diferentes especialidades, destacaram-se as publicações da área da saúde mental, saúde do idoso e nefrologia. Sobre a primeira evidenciou-se a quebra de antigos paradigmas desta temática, tais como a desinformação por parte dos profissionais sobre aspectos criativos da prática assistencial. Diante disto uma das contribuições foi desafiar o GP a se envolver em uma relação dialógica(2,1617) com os clientes.

Na área de saúde da pessoa idosa, foram desvelados trabalhos que abordaram o processo de envelhecer sobre diferentes aspectos, descrevendo inclusive os sentimentos de angústia com esta fase da vida por parte do grupo(17). O autocuidado, durante a fase de envelhecimento, compreende a busca por outra dimensão do viver. São esses confetos que caracterizam a contribuição da sociopoética nesta área ${ }^{(18)}$. Nesta temática, os resultados reafirmaram a importância do AC no processo de viver e o envelhecimento como uma sequência do desenvolvimento humano(15).

Nos estudos desenvolvidos nas áreas nefrologia e na de terapia intensiva realizado com GP formado por familiares de clientes, em estado crítico, sobrelevam-se as expressões do sentimento de medo, além da insegurança causada pelo toque físico. Na área de dermatologia ressalta-se que, a sociopoética mudou o foco do cuidar de feridas para o cuidar de pessoas em sua integralidade, introduzindo o princípio filosófico referente a dialogicidade ${ }^{(3)}$.

Os estudos realizados com pessoas vivendo com o vírus HIV e com clientes atendidos pela Estratégia Saúde da Família (ESF) abordaram a sexualidade dos acometidos pelo vírus citado, em relação aos assistidos por este atual programa. Infere-se, que a associação do tema com a "genitalidade" e com a relação heterossexual faz parte do pensamento hegemônico. Assim, torna-se necessário abrir espaço para novas produções sobre esta temática, visando evidenciar que a sexualidade abrange o corpo, o simbólico, a afetividade, a descoberta individual, o prazer e a maternidade.

Instituindo um GP formado por adolescentes, a sociopoética construiu um espaço fértil referente à expressão de sentimentos e idéias, visto estimular sua criatividade rumo à produção de subjetividade ${ }^{(3)}$. No estudo sobre obstetrícia, enfocou-se a importância da potencialização do cuidado materno. Referente ao cuidado de enfermagem, enfatizou-se características próprias do fazer feminino, que na instituição hospitalar é pouco valorizado. Pois as práticas de cuidado têm características mais masculinas, compreendidas pela cisão, reparação, extirpação do mal (doença), ou seja, características totalmente opostas às do cuidado feminino.

Independente das especialidades centradas no secular modelo biomédico, os estudos sociopoéticos, ao interessarem-se pelo cuidar, buscaram atender às múltiplas dimensões corporais. Na busca da integralidade do cliente, alvo da atenção humanista pretendida pela enfermagem, ressaltou-se que o cuidado integral é efetivamente desenvolvido somente por quem está 
próximo, junto com o cliente, convivendo e interagindo nos seus movimentos de ser e estar nessa situação ou condição do viver. Pois cuidar da integralidade do ser significa, рага a enfermagem, reconhecer o domínio de saberes, conhecimentos para guiar uma prática independente das prescrições de outros profissionais de saúde ${ }^{(11)}$.

\section{CONCLUSÃO}

Ao longo de quase duas décadas, estudos sociopoéticos foram desenvolvidos em diferentes áreas de atuação da enfermagem. Porém, diante da comunidade acadêmica é um método de produção do conhecimento relativamente recente e ainda pouco divulgado, apesar de existir registros de várias teses, dissertações e pesquisas desenvolvidas nessa perspectiva. Uma das maiores contribuições da sociopoética às pesquisas qualitativas é a concordância com a postura dialógica do pesquisador para com os sujeitos de pesquisa, construindo um espaço de crescimento mútuo entre ambos.

Esta abordagem tem contribuído para o desenvolvimento da pesquisa, do cuidado e do ensino em enfermagem, apontando a necessidade de ressignificação das concepções de pesquisadores, cuidadores e educadores, ao evidenciar seu compromisso ético com os seres humanos.

A descrição dos conceitos/conhecimentos e "confetos" integrantes das categorias e subcategorias delimitadas, a partir da produção do conhecimento nos trabalhos investigados, demonstraram a apropriação de fundamentos teóricos e princípios filosóficos da sociopoética referentes à: valorização dos indivíduos (clientes, estudantes e profissionais), considerando-os copesquisadores, que possuem saberes a priori, sendo, portanto, ativos nas artes/atos de viver/aprender/cuidar/educar, e parceiros no desenvolvimento do cuidar mais humanizado.

\section{REFERÊNCIAS}

1. Gauthier J. O oco do vento: metodologia da pesquisa sociopoética e estudos transculturais. Curitiba: CRV; 2012. 2. Santos I dos, Gauthier J, Figueiredo NMA, Petit SH (organizadores). Prática de pesquisa nas ciências humanas e sociais: abordagem sociopoética. São Paulo: Atheneu; 2005. 3. Mendes KDS, Silveira RCdCP, Galvão CM. Integrative literature review: a research method to incorporate evidence in health care and nursing. Texto e contexto Enferm [Internet]
Corroborando para isto, o GP propiciou o compartilhamento de saberes e a reflexão sobre o cuidado das pessoas nas diferentes especialidades identificadas nos estudos, possibilitando a expressão da sua dimensão imaginativa sobre aspectos existenciais inerentes à sua posição no mundo como clientes, estudantes e profissionais da área de saúde e enfermagem. A esse respeito, ressalta-se a importância de uma prática profissional e educacional aliada aos hábitos que possam resgatar a integralidade do ser humano e o cuidado planetário.

Concluiu-se que a maior contribuição da sociopoética, na atualidade, refere-se à inovação epistemológica da prática de pesquisa em enfermagem. Pois o desenvolvimento do método, centrado no dispositivo do grupo pesquisador, privilegia os informantes da pesquisa ao valorizar seus saberes, crenças e culturas, favorecendo, assim, o exercício de sua cidadania na sua convivência com o mundo da saúde, consigo e com os outros, independente de sua formação educacional e situação de saúde. Portanto, do mesmo modo que a fenomenologia doou um objeto de saber às ciências humanas e sociais, a sociopoética criou uma prática de pesquisa inerente, coerente e adequada à essência da profissão enfermagem - o cuidar.

A análise das categorias e subcategorias delimitadas nesta RIL contribuiu para reforçar a concepção de que o ato de cuidar baliza as práticas de enfermagem. Fato que justifica a motivação para pesquisar aplicando a sociopoética, pois esta sempre destaca aspectos correlacionados ao cuidado com as pessoas. Isso também justifica a predominância desta abordagem do conhecimento em diferentes pesquisas desenvolvidas por enfermeiros. Espera-se que novos estudos, em diferentes áreas possam ser realizados, contribuindo para a difusão e a interdisciplinaridade das pesquisas sociopoéticas.
2008 [cited 2012 mai 15]; 17(4):758-64. Available from:

http://www.scielo.br/pdf/tce/v17n4/18.pdf.

4. Santos I dos. Sociopoética: un puente para el cuidar / investigar en enfermería. Rev. Index de Enferm. [Internet]. 2005 [cited 2012 jun 27]; (50):35-7. Available from: http://www.indexf.com/index-enfermeria/50revista/p5233.php.

5. Gauthier JZ. Metaphor and concept in qualitative researches. Rev enferm UERJ. [Internet] 2003 [cited 2012 mai 03];

11(3):301-7. Available from:

http://www.facenf.uerj.br/v11n3/v11n3a11.pdf. 
6. Silveira LC, Almeida ANS, Macedo SM, Alencar MN, Araújo MAM. A sociopoética como dispositivo para produção de conhecimento. Rev. Interface comun saúde educ. [Internet] 2008 [cited 2012 mai 04]; 12(27):873-81. Available from: http://www.scielo.br/pdf/icse/v12n27/a16v1227.pdf. 7. Gauthier JZJ. Pour une réflexion anticolonialiste sur l'autorisation noétique, spirituelle, corporelle et politique des chercheurs. Rev enferm UERJ. [Internet] 2008 [cited 2012 mai 06]; 16(2):269-75. Available from: http://www.facenf.uerj.br/v16n2/v16n2a21.pdf.

8. Santos I dos. Taking care of student: social poetics sensitizing caretaker formation. Rev. Enferm. UERJ. [Internet] 2007 [cited 2012 mai 20];15(1):113-8. Available from:

http://www.facenf.uerj.br/v15n1/v15n1a18.pdf. 9. Santos I dos, Gauthier J, Figueiredo NMA, Tavares CMM, Brandão ES, Santana RF. The aesthetical perspective in taking care of/educating people: social poetic appropriations and contributions. Texto e contexto Enferm; 15 (n.especial):31-38. [Internet] 2006 [cited 2012 mai 19] Available from: http://www.scielo.br/pdf/tce/v15nspe/v15nspea03.pdf. 10. Santos I dos, Brandão ES, Clos AC. Enfermagem dermatológica: competências e tecnologia da escuta sensivel para atuar nos cuidados com a pele. Rev. Enferm. UERJ. [Internet] 2009 [cited 2012 ago 09]; 17(1). Available from: http://www.facenf.uerj.br/v17n1/v17n1a23.pdf.

11. Santos I dos, Caldas CP, Gauthier J, Erdmann AL, Figueiredo NMA. Cuidar da integralidade do ser: desafio no domínio da enfermagem. Rev Enferm UERJ [Internet] 2012 [cited 2012 abr 09]; 20(1). Available from:

http://www.facenf.uerj.br/v20n1/v20n1a02.pdf.

12. Figueiredo NMA, Santos I dos. Nascendo para aprender: entendendo o cuidado em saúde e enfermagem. Esc Anna Nery Rev Enferm. [Internet] 2000 [cited 2012 abr 22]; 4(2):235-42.

Available from:

http://redalyc.uaemex.mx/src/inicio/ArtPdfRed.jsp?iCve=12771 8323011.

13. Brandão ES, Santos I dos, Cavalcanti ACD, Santana RF, Queluci GC, Azevedo SL. Uma sociopoética do autocuidado: comportamento de estudantes de enfermagem visando à promoção da saúde. [Internet] 2009 [cited 2012 mai 02]; 30(2):280-8. Available from:

http://seer.ufrgs.br/RevistaGauchadeEnfermagem/article/down load/7653/6686.

14. Cameron LE, Araújo STC. Visão como instrumento da percepção na assistência em enfermagem traumato-ortopédica. Rev. Esc. Enferm. USP. [Internet] 2011 [cited $2012 \mathrm{mai}$ 03];45(1):95-9. Available from:

http://www.scielo.br/pdf/reeusp/v45n1/13.pdf.

15. Santos I dos, Alves ACS, Silva AFL, Caldas CP, Berardinelli LMM, Santana RF. O grupo pesquisador construindo ações de autocuidado para o envelhecimento saudável: pesquisa sociopoética. Esc. Anna Nery Rev. Enferm. [Internet]. 2011 [cited 2012 mar 20]; 15(4):746-54. Available from:

http://www.scielo.br/pdf/ean/v15n4/a13v15n4.pdf.

16. Alves ACS, Santos I dos. Promoting the self care of the elderly for healthy aging: application of nola pender theory. Texto e contexto Enferm. [Internet]. 2010 [cited 2012 mar 10]; 19(4):745-53. Available from:

http://www.scielo.br/pdf/tce/v19n4/18.pdf.

17. Santos I dos, Alves ACS, Silva FS, Penna LHG, Alvin NAT. Fundamentos filosóficos e teóricos para novas concepções do cuidar em enfermagem: contribuição da sociopoética. Rev Bras Enferm. [Internet] 2010 [cited 2012 mai 08]; 63(4):644-51. Available from: http://www.scielo.br/pdf/reben/v63n4/22.pdf. 18. Tavares CMM. Creative practice in psychiatric Nursing: intervening factors in its development. Esc Anna Nery Rev Enferm. [Internet] 2002 [cited 2012 mai 21]; 6(1):107-17. Available from: http://www.eean.ufrj.br/revista_enf/2002_vol06/2002_vol06n0 1ABRIL.pdf.

Artigo recebido em 31/10/2012.

Aprovado para publicação em 31/01/2013.

Artigo publicado em 31/03/2013. 